\title{
Silagem de milho e grão de sorgo como suplementos para vacas de descarte terminadas em pastagem cultivada de estação fria
}

\author{
[Corn silage and sorghum grain supplementation to cull cows finished on cultivated winter pasture] \\ L.F.G. Menezes ${ }^{1}$, L.R. Segabinazzi ${ }^{1}$, I.L. Brondani ${ }^{2}$, J. Restle ${ }^{3}$, M.Z. Arboitte ${ }^{1}$, \\ F. Kuss ${ }^{4}$, P.S. Pacheco ${ }^{3}$, J.R.P. Rosa ${ }^{4}$ \\ ${ }^{1}$ Aluno de pós-graduação - UFSM - Santa Maria, RS \\ ${ }^{2}$ Departamento de Zootecnia - UFSM - Santa Maria, RS \\ ${ }^{3}$ Universidade Federal de Goiás - Goiânia, GO \\ ${ }^{4}$ Universidade Federal do Rio Grande do Sul - Porto Alegre, RS
}

\begin{abstract}
RESUMO
Avaliou-se o efeito da suplementação com silagem de milho ou grão de sorgo no desempenho e características da carcaça e da carne de vacas de descarte, submetidas ao pastejo restrito em pastagem de aveia (Avena strigosa) + azevém (Lolium multiflorum). Foram utilizadas 30 vacas mestiças Charolês-Nelore, com idade média de oito anos, distribuídas em igual número e ao acaso em três tratamentos: silagem de milho (TSI) ou grão de sorgo moído (TSO) como suplemento, e não suplementação (TPH). A suplementação com silagem de milho proporcionou aos animais maior escore corporal ao final do experimento (4,35 pontos contra 4,15 do TPH e 4,22 pontos para o TSO). Não houve efeito do volumoso ou concentrado suplementar sobre o peso corporal, ganho de peso diário e ganho em escore corporal. Não houve efeito de tratamento $(\mathrm{P}>0,05)$ sobre pesos e rendimentos quentes e frios da carcaça, espessura de gordura subcutânea, conformação, espessura de coxão, área de Longissimus dorsi e percentagem de cortes comerciais. A suplementação resultou em maior percentagem de gordura na carcaça e influenciou a cor e o marmoreio da carne. A silagem de milho e o grão de sorgo servem como alternativa para a suplementação de vacas de descarte em pastagem de aveia e azevém, uma vez que melhora as características da carcaça, embora sem efeito sobre o desempenho quando comparado à pastagem exclusiva.
\end{abstract}

Palavras-chave: bovino, Avena strigosa, carcaça, concentrado, Lolium multiflorum, suplementação

\begin{abstract}
The effect of supplementation with corn silage or sorghum grain on the performance and characteristics of carcass and meat of cull cows, under temporary grazing on oats (Avena strigosa) + ryegrass (Lolium multiflorum) pasture was evaluated. Thirty crossbred Charolais-Nellore cull cows, with averaging eight-yearold,were randomly distributed in three treatments. The animals received corn silage (TSI) or sorghum grain (TSO) as supplement, while another lot did not receive supplementation (TPH). Animals supplemented with corn silage showed higher final body condition score (4.35 points versus 4.15 for TPH and 4.22 for TSO). No effect of supplementation on body weight, average daily weight gain; and body condition score gain were verified. Differences were not observed concerning carcasses weight, hot and cold yield of carcasses, fat thickness, conformation, cushion thickness, Longissimus dorsi area, and commercial cuts percentages. Supplemented animals showed better color and higher marbling of meat. Corn silage and sorghum grain are alternative for the supplementation of cull cows in oats and ryegrass pasture, since they showed better carcass characteristics, although no effect on the performance in relation to exclusive pasture was detected.
\end{abstract}

Keywords: cattle, Avena strigosa, carcass, Lolium multiflorum, corn silage, sorghum grain, supplementation

Recebido em 11 de abril de 2008

Aceito em 3 de novembro de 2008

E-mail:1fgdm@yahoo.com.br 


\section{INTRODUÇ̃̃O}

Grande parte do abate e consequentemente da carne consumida é oriunda de vacas de descarte (Anuário..., 2007). Essa categoria animal tende a ser comercializada no período de outono, após o diagnóstico de gestação dos rebanhos, período de preços mais baixos em razão da maior oferta. No sul do Brasil, a comercialização no período de agosto a outubro, quando se obtêm melhores preços, é uma alternativa para aumentar a rentabilidade dos produtores. Para que isso ocorra, torna-se indispensável o investimento em alimentação, pois as condições do campo nativo do sul do Brasil não oferecem meios de produzir animais cuja carcaça atenda às exigências dos frigoríficos.

Surgem, então, como alternativas, a utilização de pastagens cultivadas de inverno e, em sistemas ainda mais intensivos, a suplementação energética. Segundo Reis et al. (1997), a suplementação acelera o ganho de peso dos animais, pois aumenta o consumo total de energia, corrige deficiências de nutrientes das pastagens, aumenta a capacidade de suporte da pastagem, além de condicionar a possibilidade de fornecer aditivos, melhorando com isso o desempenho animal. Porém, a escolha do tipo de suplemento é de fundamental importância para o sucesso econômico, pois, de acordo com Pilau et al., (2003), o custo do suplemento é um fator determinante na economicidade da suplementação em pastagens cultivadas de inverno.

O grão de sorgo é boa alternativa na alimentação animal (Faturi et al., 2003). Restle et al. (2001b) observaram aumento no ganho de peso médio diário e no ganho em estado corporal de vacas de descarte, ao utilizarem maiores níveis de grão de sorgo na suplementação em pastagem de aveia + azevém. Esses autores não observaram efeito da suplementação sobre as características da carcaça.

O uso da silagem de milho como suplemento surge como alternativa que pode amenizar as despesas com a alimentação, visto que é um alimento volumoso com um bom teor de energia e de custo menor por unidade energética do que os grãos e farelos, sem prejudicar o desempenho dos animais (Alves Filho et al., 2001). Existem poucas (Heck et al., 2006; Silveira et al., 2006) pesquisas testando o uso de volumosos suplementares, pois geralmente os produtores optam pela utilização de suplementos protéicos e/ou energéticos.

O presente experimento foi realizado com o objetivo de avaliar a utilização de silagem de milho e do grão de sorgo moído como suplemento no desempenho e nas características da carcaça e da carne de vacas de descarte, de diferentes idades, mantidas em pastejo restrito em pastagem de aveia (Avena strigosa) + azevém (Lolium multiflorum).

\section{MATERIAL E MÉTODOS}

O experimento foi realizado no Laboratório de Bovinocultura de Corte do Departamento de Zootecnia da Universidade Federal de Santa Maria (UFSM). O município está situado na Depressão Central do estado, numa altitude de $95 \mathrm{~m}$, latitude $29^{\circ} 43^{\prime} \mathrm{Sul}$ e longitude $53^{\circ}$ $42^{\prime}$ Oeste. Conforme citado por Moreno (1961), o clima da região é Cfa (subtropical úmido) com possibilidade de estiagem no verão. O experimento foi realizado no período de 12 de julho a 24 de outubro e composto de cinco períodos, com 21 dias cada, totalizando 105 dias.

Foram utilizadas 30 vacas de descarte Charolês, Nelore e suas cruzas, tomadas ao acaso do rebanho experimental da UFSM. Os animais foram terminados em pastagem de aveia (Avena strigosa) + azevém (Lolium multiflorum). Pela manhã, das 8 às $10 \mathrm{~h}$ e $30 \mathrm{~min}$, todos os animais pastejavam a mesma área com 6ha. À tarde, das 14 às $16 \mathrm{~h}$ e $30 \mathrm{~min}$, os animais foram distribuídos em: 10 animais que retornaram à pastagem (TPH), 10 que receberam a quantidade de $1,25 \%$ do peso vivo (PV), na base seca, de silagem de milho (TSI), e 10 que receberam $1,25 \%$ do PV, na base seca, de grão de sorgo moído (TSO). Em cada tratamento havia animais de todas as classes de idade. À noite, permaneceram em área de campo nativo onde havia sal e água à vontade. Caso houvesse sobras de suplemento, estas eram recolhidas e pesadas para posterior cálculo do consumo total do suplemento.

As vacas foram pesadas no início, no final e no intervalo de cada período experimental, sempre seguido de jejum de sólidos e líquidos por 15 horas. Junto às pesagens, foi avaliado o escore corporal (EC) por meio de notas dadas por três 
avaliadores treinados, em que: 1 = muito magro; $2=$ magro; $3=$ médio; $4=$ gordo; $5=$ muito gordo.

Para estabelecimento da pastagem, foram utilizados $80 \mathrm{~kg} / \mathrm{ha}$ de semente de aveia preta (Avena strigosa) e $25 \mathrm{~kg} / \mathrm{ha}$ de azevém (Lolium multiflorum) semeados por meio de plantio direto em linha e, posteriomente, a lanço, mais $25 \mathrm{~kg} / \mathrm{ha}$ de azevém. Na adubação de base, foram utilizados $370 \mathrm{~kg} / \mathrm{ha}$ da fórmula 10-18-20. Na de cobertura, $300 \mathrm{~kg} / \mathrm{ha}$ de ureia, fracionados em três aplicações. Para a determinação da massa de forragem, foi utilizada, em cada período experimental, a técnica da dupla amostragem descrita por Mannetje (2000). Foram realizadas simulações de pastejo a cada 10 dias durante o período experimental, visando coletar amostras da pastagem similar à consumida. Posteriomente, fez-se a separação botânica da amostra para quantificar azevém, aveia, material senecente e outros. Do restante das amostras, após a homogeneização, foi retirada uma amostra composta, pesada e levada à estufa com circulação de ar forçado a $55^{\circ} \mathrm{C}$, por, no mínimo, 72 horas. Após a secagem, estas foram pesadas, para determinar o teor de matéria parcialmente seca, e moídas em moinho tipo Wiley, com peneira de malha de $1 \mathrm{~mm}$, para então serem embaladas para posteriores análises químicas e de digestibilidade in vitro da matéria orgânica (DIVMO), realizadas em laboratório especializado. $\mathrm{Na}$ análise bromatológica, o grão de sorgo apresentou concentração de $6,9 \%$ de $\mathrm{PB}$, e a silagem de milho $9,3 \%$ de $\mathrm{PB}$. Os resultados produtivos e qualitativos da pastagem encontram-se na Tab. 1.

Tabela 1. Digestibilidades in vitro da matéria orgânica (DIVMO) e da matéria seca (DIVMS) da simulação de pastejo, massa de forragem (MF), carga animal (CAN) e participação dos constituintes da pastagem de acordo com o período experimental

\begin{tabular}{lcccccc} 
Variável & $12 / 07 \mathrm{a}$ & $02 / 08 \mathrm{a}$ & $23 / 08 \mathrm{a}$ & $13 / 09 \mathrm{a}$ & $04 / 10 \mathrm{a}$ & \multirow{2}{*}{ Média } \\
\hline DIVMO, \% & $01 / 08$ & $22 / 08$ & $12 / 09$ & $03 / 10$ & $24 / 10$ & 56,07 \\
DIVMS, \% & 59,80 & 58,78 & 53,82 & 56,72 & 51,25 & 56,89 \\
MF, kgMS/ha & 58,75 & 60,89 & 56,18 & 57,19 & 51,45 & 1809 \\
CAN, kg PV/ha/dia & 1588 & 1506 & 1418 & 2128 & 2406 & 1895,3 \\
Constituinte, \% & 1897,0 & 1974,0 & 2101,7 & 1159,8 & 2344,2 & \\
Aveia & & & & & & \\
Azevém & 36,60 & 36,15 & 36,15 & 25,78 & 0,00 & 26,94 \\
Material morto & 42,80 & 26,33 & 23,14 & 38,23 & 34,78 & 33,06 \\
Outros & 13,00 & 18,94 & 16,89 & 20,41 & 36,47 & 21,14 \\
\hline
\end{tabular}

Após 105 dias de experimento e de um jejum de sólidos de 14 horas, os animais foram pesados e embarcados para um frigorífico comercial, onde foram abatidos logo na chegada. Em seguida, as carcaças foram identificadas, pesadas e levadas para uma câmara fria, onde permaneceram por 24 horas a $0^{\circ} \mathrm{C}$. Após esse tempo, as carcaças foram novamente pesadas e, seguindo a metodologia descrita por Müller (1987), avaliadas quanto à conformação e à maturidade fisiológica.

A metade esquerda da carcaça foi separada em dianteiro, costilhar (ponta de agulha) e serrote (traseiro especial), e cada peça foi pesada para posterior cálculo da percentagem dessas peças em relação à carcaça inteira.
$\mathrm{Na}$ meia carcaça direita, seguindo a metodologia proposta por Müller (1987), tomaram-se as medidas de comprimento de carcaça e de perna, espessura de coxão e perímetro de braço. Entre a $12^{\mathrm{a}}$ e $13^{\mathrm{a}}$ costela, realizou-se um corte horizontal visando expor o músculo Longissimus dorsi para traçar o seu contorno em papel vegetal, sendo a área da figura posteriormente determinada em mesa digitalizadora por meio do uso do software Site10. No mesmo local, foi medida a espessura de gordura subcutânea obtida pela média de duas observações, além das avaliações subjetivas de marmoreio, cor e textura da carne, sendo para isso seccionado o músculo $L$. dorsi na altura da $12^{\mathrm{a}}$ costela, conforme metodologia descrita por Müller (1987). Para determinar as percentagens de músculo, gordura e osso, seguiu-se a metodologia descrita por Hankins e Howe (1946), adaptadas por Müller (1973), sendo que a 
porção do músculo $L$. dorsi extraída dessas determinações foi identificada, embalada e congelada para posterior determinação de características laboratoriais.

Em laboratório, do músculo congelado foram extraídas quatro fatias de $2,5 \mathrm{~cm}$ de espessura, obtidas perpendicularmente ao comprimento do músculo, as quais foram utilizadas para avaliação das características sensoriais (fatia A), avaliações da quebra ao descongelamento, quebra à cocção e resistência das fibras ao corte (fatia B).

As características sensoriais da carne foram avaliadas conforme os métodos descritos por Müller (1987). Para cálculo das perdas ao descongelamento e à cocção, foi realizada a pesagem da fatia $\mathrm{B}$, ainda congelada, depois de descongelada e após o cozimento, que ocorreu até que a temperatura interna da fatia atingisse $70^{\circ} \mathrm{C}$. A pesagem após o cozimento foi realizada assim que a amostra voltou à temperatura ambiente.

Em seguida ao cozimento e à pesagem das fatias $B$, foram extraídas três amostras de feixes de fibras, circulares, com $1 \mathrm{~cm}^{3}$ de área, as quais foram cortadas perpendicularmente à fibra, por intermédio do aparelho Warner-Bratzler Shear.

O delineamento experimental utilizado foi $\mathrm{o}$ inteiramente ao acaso, e os resultados coletados foram submetidos à análise de variância. As médias dos tratamentos foram comparadas pelo teste Tukey, usando-se o programa SAS (User's..., 1997).

\section{RESULTADOS E DISCUSSÃO}

Na Tab. 2 estão expressos os dados referentes ao desempenho dos animais de acordo com o tipo de suplemento.

Tabela 2. Médias e erros-padrão para peso inicial e final, escore corporal inicial e final, ganho médio diário de peso e de escore corporal de vacas de descarte de acordo com a fonte energética usada como suplemento na pastagem cultivada de inverno

\begin{tabular}{lccc} 
& & & \\
& TPH & TSO & TSI \\
\hline Peso inicial, $\mathrm{kg}^{1}$ & $358,67 \pm 8,2$ & $372,61 \pm 8,2$ & $356,00 \pm 8,7$ \\
Peso final, kg & $475,22 \pm 9,7$ & $482,40 \pm 9,7$ & $476,00 \pm 10,3$ \\
Escore corporal inicial, pontos $^{1}$ & $2,84 \pm 0,05$ & $2,96 \pm 0,05$ & $2,89 \pm 0,05$ \\
Escore corporal final, pontos & $4,15 \pm 0,04 \mathrm{~B}$ & $4,22 \pm 0,04 \mathrm{~B}$ & $4,35 \pm 0,04 \mathrm{~A}$ \\
Ganho de peso médio diário, kg/dia & $1,110 \pm 0,07$ & $1,046 \pm 0,07$ & $1,144 \pm 0,07$ \\
Ganho em escore corporal, pontos/dia & $0,262 \pm 0,03$ & $0,251 \pm 0,03$ & $0,292 \pm 0,03$ \\
\hline
\end{tabular}

${ }^{1}$ Efeito do manejo alimentar retirado do modelo.

TPH: pastejo de 2,5h pela manhã e à tarde (grupo-controle); TSO: pastejo de 2,5h pela manhã e suplementação de $1,25 \%$ do peso vivo com grãos de sorgo moído; TSI: pastejo de 2,5h pela manhã e suplementação de $1,25 \%$ do peso vivo com $1,25 \%$ do peso vivo com silagem de milho.

Valores seguidos por letras distintas na linha diferem entre si pelo teste Tukey $(\mathrm{P}<0,05)$.

Houve efeito $(\mathrm{P}<0,05)$ de tratamento apenas para o escore corporal final, sendo mais alto nos animais que receberam silagem de milho. $\mathrm{O}$ incremento do EC é desejável pelo fato de possibilitar a comercialização antecipada dos animais, como mencionaram Restle et al. (2001a). A capacidade da suplementação com silagem de milho para a melhoria da condição corporal dos animais também foi constatada por Heck et al. (2006), que, ao aumentarem o nível de consumo de vacas de descarte suplementadas com silagem de milho em pastagem hibernal, de 0,99 para $1,07 \%$ do peso vivo, observaram melhora na condição corporal em 4,7\%. Essa maior condição corporal de animais suplementados com silagem de milho não era esperada, uma vez que a densidade energética do grão de sorgo é maior que a da silagem de milho. Pode ter acontecido algum efeito associativo entre a pastagem e a silagem que favoreceu esse parâmetro. $\mathrm{O}$ efeito associativo entre alimentos ocorre quando a digestibilidade da mistura de alimentos é igual à soma das digestibilidades dos componentes obtidos isoladamente (Mould, 1988). Assim, de acordo com Nussio et al. (2001), a combinação do valor nutritivo de certos alimentos pode causar dois efeitos distintos, positivo ou negativo. No entanto, essa conclusão é meramente especulativa.

$\mathrm{Na}$ Austrália, Stockdale (1995) apresentou restrições à suplementação exclusiva com 
silagem de milho sobre o desempenho de vacas leiteiras em pastejo de azevém perene (Lolium perenne).

Observou-se semelhança $(\mathrm{P}>0,05)$ entre todos os tratamentos para o ganho de peso médio diário (GMD). A maior densidade energética do grão de sorgo também poderia trazer a expectativa de melhor GMD para esse suplemento, o que não ocorreu, semelhante aos resultados obtidos por Alves Filho et al. (2001) e Silveira et al. (2006). $\mathrm{O}$ fato de o grão de sorgo apresentar grande quantidade de amido, que é responsável pela rápida fermentação ruminal, resulta na queda do $\mathrm{pH}$, fato este que, segundo Terry et al. (1969), provoca inibição da celulólise. Forbes (1995) observou que o uso de silagens como suplemento reduz a ingestão de MS e que sua utilização como suplemento mantém o $\mathrm{pH}$ ruminal adequado para o crescimento de bactérias celulolíticas, responsáveis pela digestão da celulose, hemicelulose e pectina, fontes de energia para os ruminantes.

Considerando que a suplementação acarreta benefícios em relação à carga animal suportada pela pastagem, já comprovado por várias pesquisas (Frizzo et al., 2003; Pilau et al., 2004), a igualdade entre os tratamentos no desempenho dos animais é uma vantagem para a silagem de milho, pois o uso deste suplemento é mais barato do que o uso de grãos. A taxa de substituição média encontrada para utilização de silagens de milho e/ou sorgo foi de 0,66 no trabalho de Vogel et al. (1989), quando esses autores utilizaram estas silagens para suplementação de novilhos de corte em pastejo de capim-bermuda (Cynodon dactylon).

$\mathrm{Na}$ Tab. 3, constam as características da carcaça dos animais de acordo com o sistema de alimentação.

Tabela 3. Médias e erros-padrão para as características da carcaça de vacas de descarte de acordo com a fonte energética usada como suplemento na pastagem cultivada de inverno

\begin{tabular}{lccc} 
& TPH & TSO & TSI \\
\hline Peso de abate, $\mathrm{kg}$ & $482,10 \pm 28,1$ & $482,36 \pm 26,8$ & $480,11 \pm 28,1$ \\
Peso de carcaça quente, kg & $261,90 \pm 16,3$ & $265,27 \pm 15,6$ & $259,11 \pm 17,2$ \\
Peso de carcaça fria, kg & $255,78 \pm 16,2$ & $258,13 \pm 17,1$ & $253,24 \pm 15,5$ \\
Rendimento de carcaça quente, $\%$ & $54,24 \pm 0,8$ & $54,88 \pm 0,7$ & $53,95 \pm 0,8$ \\
Rendimento de carcaça fria, \% & $52,95 \pm 0,8$ & $53,38 \pm 0,8$ & $52,71 \pm 0,8$ \\
Espessura de gordura, mm & $4,95 \pm 0,8$ & $5,86 \pm 0,8$ & $5,44 \pm 0,8$ \\
Conformação, pontos ${ }^{1}$ & $9,00 \pm 0,4$ & $9,27 \pm 0,3$ & $9,44 \pm 0,4$ \\
Espessura de coxão, cm & $28,90 \pm 0,8$ & $28,73 \pm 0,8$ & $27,89 \pm 0,9$ \\
Área de Longissimus dorsi, cm $^{2}$ & $67,92 \pm 4,4$ & $68,73 \pm 4,2$ & $71,34 \pm 4,7$ \\
\hline
\end{tabular}

TPH: pastejo de 2,5h pela manhã e à tarde (grupo-controle); TSO: pastejo de 2,5h pela manhã e suplementação de $1,25 \%$ do peso vivo com grãos de sorgo moído; TSI: pastejo de 2,5 h pela manhã e suplementação de $1,25 \%$ do peso vivo com $1,25 \%$ do peso vivo com silagem de milho.

Nenhuma característica quantitativa da carcaça foi influenciada pelos tratamentos. As semelhanças entre características quantitativas da carcaça podem ser atribuídas ao peso semelhante de abate, pois essas características são altamente relacionadas (Euclides Filho et al., 1997) quando o rendimento de carcaça não é afetado.

No presente estudo, esperava-se diferença no rendimento de carcaça dos animais, devido ao tipo de tratamento empregado (volumoso $\mathrm{x}$ concentrado), como foi encontrado por Euclides Filho et al. (1997). No entanto, tanto a pastagem como a silagem de milho eram de boa qualidade e apresentavam boa digestibilidade $(56,07$ e $69 \%$, respectivamente). Restle et al. (2001a) verificaram que, quando o volumoso apresenta alta taxa de passagem, não são encontradas diferenças no rendimento de carcaça entre animais alimentados com diferentes níveis de concentrado.

A espessura de gordura subcutânea ficou dentro dos limites desejados, acima de $3 \mathrm{~mm}$, para prover melhor proteção contra o escurecimento e o frio, e abaixo de $6 \mathrm{~mm}$, evitando o recorte da carcaça para retirada do excesso de gordura. A deposição de gordura no animal está altamente relacionada ao peso de abate (Arboitte et al., 2004), ao grupo genético (Menezes et al., 2005), à idade do animal e à densidade energética da dieta (Restle et al., 2001a). Considerando os 
fatores acima citados, os tratamentos diferiram apenas quanto à densidade energética, sendo que o grão de sorgo apresentou 3,59 Mcal de energia digestível $/ \mathrm{kg}$ de MS, e a silagem 2,85 Mcal $/ \mathrm{kg}$ de MS. No entanto, essa diferença não foi suficiente para proporcionar maior deposição de gordura.

$\mathrm{Na}$ Tab. 4 são apresentados os resultados referentes à composição física e da participação dos cortes comerciais na carcaça. A suplementação com grão de sorgo moído proporcionou carcaças com maior participação de gordura em relação às carcaças do grupo da pastagem. As carcaças oriundas de animais suplementados com silagem de milho ficaram em posição intermediária. Essa maior participação de gordura na carcaça do tratamento com grão de sorgo resultou em carcaças com menor participação de músculo. Segundo Berg e Butterfield (1976), entre os tecidos que compõem a carcaça, o muscular é o mais importante por ser o mais procurado pelo consumidor. Portanto, a carcaça deve apresentar quantidade máxima de músculo, mínima de ossos e quantidade de gordura que varia de acordo com a preferência do consumidor.

Os valores referentes às características qualitativas da carne das vacas de descarte estão expressos na Tab. 5 .

Tabela 4. Médias e erros-padrão da composição física e participação dos cortes comerciais da carcaça de vacas de descarte de acordo com a fonte energética usada como suplemento na pastagem cultivada de inverno

\begin{tabular}{lccc}
\hline & TPH & TSO & TSI \\
\hline Músculo, \% & $64,96 \pm 1,8 \mathrm{~A}$ & $58,99 \pm 1,8 \mathrm{~B}$ & $64,50 \pm 1,8 \mathrm{~A}$ \\
Gordura, \% & $20,23 \pm 2,1 \mathrm{~B}$ & $25,85 \pm 2,1 \mathrm{~A}$ & $22,17 \pm 2,3 \mathrm{AB}$ \\
Osso, \% & $15,15 \pm 0,8$ & $13,97 \pm 0,9$ & $15,23 \pm 0,8$ \\
Dianteiro, \% & $37,53 \pm 0,4$ & $36,77 \pm 0,4$ & $37,27 \pm 0,4$ \\
Costilhar, \% & $12,18 \pm 0,3$ & $12,12 \pm 0,3$ & $12,42 \pm 0,4$ \\
Traseiro, \% & $50,29 \pm 0,3$ & $50,60 \pm 0,3$ & $50,80 \pm 0,3$ \\
\hline
\end{tabular}

TPH: pastejo de 2,5h pela manhã e à tarde (grupo-controle); TSO: pastejo de 2,5h pela manhã e suplementação de $1,25 \%$ do peso vivo com grãos de sorgo moído; TSI: pastejo de $2,5 \mathrm{~h}$ pela manhã e suplementação de $1,25 \%$ do peso vivo com $1,25 \%$ do peso vivo com silagem de milho.

Valores seguidos por letras distintas na linha diferem entre si pelo teste Tukey $(\mathrm{P}<0,05)$.

Tabela 5. Médias e erros-padrão para as características qualitativas da carne de vacas de descarte de acordo com o tipo de fonte energética usada como suplemento na pastagem cultivada de inverno

\begin{tabular}{|lccc}
\hline & TPH & TSO & TSI* $^{*}$ \\
\hline Cor, pontos $^{1}$ & $3,20 \pm 0,2 \mathrm{~B}$ & $4,00 \pm 0,2 \mathrm{~A}$ & $3,78 \pm 0,2 \mathrm{AB}$ \\
Textura, pontos $^{2}$ & $3,10 \pm 0,3$ & $3,18 \pm 0,3$ & $3,67 \pm 0,3$ \\
Marmoreio, pontos $^{3}$ & $4,20 \pm 1,0 \mathrm{~B}$ & $7,09 \pm 1,0 \mathrm{~A}$ & $6,78 \pm 1,1 \mathrm{~A}$ \\
Maciez, pontos $^{4}$ & $6,15 \pm 0,2$ & $6,10 \pm 0,2$ & $6,50 \pm 0,2$ \\
Palatabilidade, pontos $^{4}$ & $6,33 \pm 0,2$ & $6,13 \pm 0,2$ & $6,58 \pm 0,2$ \\
Suculência, pontos $^{4}$ & $6,41 \pm 0,2$ & $6,43 \pm 0,1$ & $6,50 \pm 0,2$ \\
Força de cisalhamento, kgF & $4,31 \pm 0,4$ & $3,94 \pm 0,4$ & $3,48 \pm 0,4$ \\
Quebra ao descongelamento, $\%^{\text {Quebra à cocção, \% }}$ & $13,87 \pm 1,3$ & $12,83 \pm 1,2$ & $11,55 \pm 1,3$ \\
\hline
\end{tabular}

${ }^{1}$ Cor: 1=escura; $2=$ vermelho escuro; $3=$ =vermelho levemente escuro; 4=vermelho; $5=$ =vermelho vivo.

${ }^{2}$ Textura: $1=$ muito grosseira; $2=$ grosseira; $3=$ levemente grosseira; $4=$ fina; $5=$ muito fina.

${ }^{3}$ Marmoreio: 1 a $3=\operatorname{traços;~} 4$ a $6=$ leve; 7 a 9=pequeno; 10 a 12=médio; 13 a 15=moderado; 16 a 18=abundante.

${ }^{4}$ Escala de 1 a 9 pontos (quanto maior o valor, mais macia, palatável e suculenta é a carne).

TPH: pastejo de 2,5h pela manhã e à tarde (grupo-controle); TSO: pastejo de 2,5h pela manhã e suplementação de $1,25 \%$ do peso vivo com grãos de sorgo moído; TSI: pastejo de 2,5 h pela manhã e suplementação de $1,25 \%$ do peso vivo com $1,25 \%$ do peso vivo com silagem de milho.

Valores seguidos por letras distintas na linha diferem entre si pelo teste Tukey $(\mathrm{P}<0,05)$. 
A suplementação proporcionou carnes mais claras e com teor de marmoreio maior que a carne dos animais não suplementados. Vaz et al. (2005) não observaram diferença na cor da carne com o aumento do nível energético da dieta. Boggs e Merkel (1981) comentaram que a coloração da carne tende a tornar-se mais escura, em virtude do aumento na quantidade de mioglobina, com o avançar da idade dos animais, tornando-se um dos inconvenientes ao abate de animais com maior idade. Ao estudarem o efeito da realimentação de vacas de descarte em confinamento, Cranwell et al. (1996) verificaram que períodos de alimentação de 56 dias com dietas energéticas são suficientes para promover redução na quantidade de mioglobina da carne, resultando em carnes com coloração mais clara. No presente estudo, a cor da carne das vacas foi classificada de vermelho levemente escuro a vermelho; os animais que receberam maior densidade energética na dieta apresentaram carnes mais claras.

O marmoreio é uma característica importante, pois está intimamente relacionado às características sensoriais da carne possíveis de serem percebidas e apreciadas pelo consumidor. A suplementação com grão de sorgo melhorou a marmorização da carne em $68,8 \%(\mathrm{P}<0,05)$, e a suplementação com silagem de milho o fez em $61,4 \% \quad(\mathrm{P}<0,05)$. Berg e Butterfield (1976) acreditam em uma ordem lógica de deposição de diferentes tipos de gordura, citando o marmoreio como a última gordura a ser depositada. Essa teoria é discutida por outros autores (Di Marco, 1998), os quais acreditam que vários fatores influenciam essa ordem, como alterações da curva de crescimento ou diferenças de níveis alimentares em diferentes fases da vida. Como a espessura de gordura não apresentou diferença entre os tratamentos, acredita-se que, com maior tempo de terminação, a carne das vacas que não receberam suplementação apresentaria marmorização semelhante à dos animais dos demais tratamentos.

As características organolépticas da carne não foram afetadas pelos tratamentos. Di Marco (1998) associou a maciez da carne à maior deposição de gordura intramuscular, e, portanto, à maior facilidade de rompimento dos sarcômeros e das fibras da carne. Porém, os maiores teores de marmoreio dos animais suplementados não afetaram a maciez e a força de cisalhamento.

\section{CONCLUSÃO}

A silagem de milho como suplemento em pastagem cultivada de inverno melhora a condição corporal de vacas de descarte, embora não altere o desempenho dos animais e não modifique as características quantitativas e qualitativas da carcaça e da carne em relação ao tratamento com grão de sorgo moído. A suplementação com silagem de milho é recomendada por resultar em maior participação de músculo na carcaça em relação à suplementação com grão de sorgo moído, além de apresentar carne com maior marmorização em relação a vacas terminadas em pastagem de aveia e azevém sem suplementação.

\section{REFERÊNCIAS BIBLIOGRÁFICAS}

ALVES FILHO, D.C.; RESTLE, J.; SOUZA, A.N.M. et al. Desempenho de vacas de descarte mantidas em campo nativo suplementadas com silagem de milho ou casca do grão da soja. In: REUNIÃO ANUAL DA SOCIEDADE BRASILEIRA DE ZOOTECNIA, 38., 2001, Piracicaba. Anais... Piracicaba: SBZ, 2001. CD ROM.

ANUÁRIO estatístico da produção animal ANUALPEC. São Paulo: Prol Editora Gráfica, 2007. $364 \mathrm{p}$.

ARBOITTE, M.Z.; RESTLE, J.; ALVES FILHO, D.C. et al. Composição física da carcaça, qualidade da carne e conteúdo de colesterol no músculo Longissimus dorsi de novilhos 5/8 Nelore - 3/8 Charolês terminados em confinamento e abatidos em diferentes estádios de maturidade. Rev. Bras. Zootec., v.33, p.959-968, 2004.

BERG, R.T.; BUTTERFIELD, R.M. New concepts of cattle growth. New York: Sydney University, 1976. 240p.

BOGGS, D.L.; MERKEL, R.A. Live animal: carcass evaluation and selection manual. Iowa: Michigan University, 1981. 199p.

CRANWELL, C.D.; UNRUH, J.A.; BRETHOUR, J.R. et al. Influence of steroid implants and concentrate feeding on carcass and Longissimus muscle sensory and collagen characteristics of cull beef cows. J. Anim. Sci., v.74, p.1777-1783, 1996.

DI MARCO, O. Crescimiento de vacunos para carne. Mar del Plata: Balcare, 1998. 245p. 
EUCLIDES FILHO, K.; EUCLIDES, V.P.B.; FIGUEIREDO, G.R. et al. Avaliação de animais Nelore e de seus mestiços com Charolês, Fleckvieh e Chianina, em três dietas. 2. Características de carcaça. Rev. Bras. Zootec., v.26, p.73-79, 1997.

FATURI, C.; RESTLE, J.; BRONDANI, I.L. et al. Grão de aveia preta em substituição ao grão de sorgo para alimentação de novilhos na fase de terminação. Rev. Bras. Zootec., v.32, p.437-448, 2003.

FORBES, J.M. Voluntary food intake and diet selection in farm animals. Wallingford, UK: CAB International, 1995.

FRIZZO, A.; ROCHA, M.G.; RESTLE, J. et al. Suplementação energética na recria de bezerras de corte mantidas em pastagem de inverno. Rev. Bras. Zootec., v.32, p.643-652, 2003.

HANKINS, O.G.; HOWE, P.E. Estimation of the composition of beef carcasses and cuts. Washington, DC: USDA, 1946. 21p. (Technical Bulletin, USDA n.926). 21p.

HECK, I.; BRONDANI, I.L.; MENEZES, L.F.G. et al. Suplementação com diferentes níveis de silagem de milho para vacas de descarte de diferentes grupos genéticos submetidas ao pastejo horário. Cienc. Rural, v.36, p.203-208, 2006.

MANNETJE, L.T. Measuring biomass of grassland vegetation. In: MANNETJE, L.T.; JONES, R.M. (Eds). Field and laboratory methods for glassland and animal production reseach. Cambridge: CAB, 2000. p.151-178.

MENEZES, L.F.G.; RESTLE, J.; BRONDANI, I.L. Características da carcaça de novilhos de gerações avançadas do cruzamento alternado entre as raças Charolês e Nelore, terminados em confinamento. Rev. Bras. Zootec., v.34, p.934-945, 2005.

MOULD, F.L. Associative effects of feeds. p.279-292. In: ORSKOV, E.R. (Ed). Feed Science. Amsterdam: Elsevier, 1988. 336p.

MÜLLER, L. Normas para avaliação de carcaças e concurso de carcaça de novilhos. 2.ed. Santa Maria: Imprensa Universitária, 1987. 31p.

MÜLLER, L. Técnicas para determinar la composición de la canal. In: _ Memoria de la Asociación Latinoamericana de Producción Animal, Guadalajara: ALPA, 1973. p.75.

NUSSIO, L.G.; CAMPOS, F.P.; MANZANO, R.P. et al. Volumosos suplementares na produção de bovinos de corte em pastagens. In: REUNIÃO ANUAL DA SOCIEDADE BRASILEIRA DE ZOOTECNIA, 38.,
2001, Piracicaba. Anais ... Piracicaba: SBZ, 2001, CD ROM.

PILAU, A.; ROCHA, M.G., SANTOS, D.T. Análise econômica de sistemas de produção para recria de bezerras de corte. Rev. Bras. Zootec., v.32, p.966-976, 2003.

PILAU, A.; ROCHA, M.G.; RESTLE, J. et al. Recria de novilhas de corte com diferentes níveis de suplementação energética em pastagem de aveia preta e azevém. Rev. Bras. Zootec., v.33, p.2104-2113, 2004.

REIS, R.A.; RODRIGUES, L.R.; PEREIRA, J.R.A. et al. A suplementação como estratégia de manejo de pastagem. In: SIMPÓSIO SOBRE MANEJO DA PASTAGEM, 13., 1997, Piracicaba. Anais... Piracicaba: FEALQ, 1997. p.123-171

RESTLE, J.; VAZ, F.N.; ALVES FILHO, D.C. et al. Efeito da suplementação energética sobre a carcaça de vacas de diferentes idades, terminadas em pastagem cultivada de estação fria sob pastejo horário. Rev. Bras. Zootec., v.30, p.1076-1083, 2001 a.

RESTLE, J.; VAZ, F.N.; ROSO, C. et al. Desempenho e características de carcaça de vacas de diferentes grupos genéticos, submetidas a níveis de suplementação energética em pastagem cultivada de estação fria. Rev. Bras. Zootec., v.30, p.1813-1823, 2001b.

SILVEIRA, M.F.; KOZLOSKI, G.; BRONDANI, I.L. et al. Ganho de peso e fermentação ruminal em novilhos mantidos em pastagem cultivada de clima temperado e recebendo diferentes suplementos. Cienc. Rural, v.36, p.898-903, 2006.

STOCKDALE, C.R. Maize silage as a supplement for pasture-fed dairy cows in early and late lactation. Austr. J. Exp. Agric., v.35, p.19-26, 1995.

TERRY, R.A.; TILLEY, J.M.; OUTEN, G.A. et al. Effect of $\mathrm{pH}$ on cellulose digestion under in vitro conditions. J. Sci. Food Agric., v.20, p.317-320, 1969.

USER'S guide: statistics. SAS for windows. Washington: SAS Institute, 1997. 946p.

VAZ, F.N.; RESTLE, J.; SILVA, N.L.Q. et al. Nível de concentrado, variedade da silagem de sorgo e grupo genético sobre a qualidade da carcaça e da carne de novilhos confinados. Rev. Bras. Zootec., v.34, p.239248, 2005.

VOGEL, G.J.; PHILLIPS, W.A.; HORN, G.W. et al. Effects of supplemental silage on forage intake and utilization by steers grazing wheat pasture in bermudagrass. J. Anim. Sci., v.67, p.232-240, 1989. 